\title{
Respiratory symptoms in West Sussex firemen
}

\author{
K HORSFIELD, FIONA M COOPER, MAUREEN P BUCKMAN, A R GUYATT, \\ G CUMMING
}

From the Department of Clinical Science, The Cardiothoracic Institute, Midhurst GU29 OBL, UK

ABSTRACT There are few reports of long term follow up of symptoms in firemen. In a four year study of symptoms in a group of 96 firemen (31 non-smokers, 40 smokers, and 25 ex-smokers) of which 89 remained in the study for its full duration a volunteer control group of 69 male non-smokers from a variety of occupations was also followed up. A history of symptoms and of smoking habits was obtained on entry to the study, then every six months for two years, and annually for a further two years. All those remaining in the study after four years were interviewed and a history of their use of breathing apparatus and of being affected by smoke and fumes was obtained. Symptom frequency was least in control subjects, intermediate in non-smokers and ex-smokers, and most in smokers. Before the study period (history obtained at the first session) smoking increased symptoms 3.9 times and being affected by smoke in the past increased symptoms $2 \cdot 3$ times, compared with non-smokers who had not been affected by smoke. In smokers who had also been affected by smoke symptoms increased by $9 \cdot 1$ times, suggesting a multiplicative effect. During the study period symptom frequency was increased about 4.4 times in smokers and 5.7 times in those who had been affected by smoke at work in the past compared with non-smokers who had not been affected by smoke. In smokers who had also been affected by smoke symptom frequency increased by 7.4 times, the combined effects of the two types of smoker being less than additive. These results suggest that being affected by smoke and fumes at work may be a cause of long term symptoms in firemen. In firemen who are non-smokers and who had not been affected by smoke symptom frequency was similar to that observed in the control subjects. Thus the current routine use of breathing apparatus appears to be effective in preventing long term symptoms.

Acute exposure to irritant or toxic gases and fumes while fighting a fire can cause symptoms in firemen both during and shortly after the event, but few long term follow up studies have been carried out. Axford et al found that 20 out of 35 firemen exposed to isocyanate fumes had persistent symptoms four years later, although a proportion of these could be attributed to smoking. ${ }^{\prime}$ By contrast, Tashkin et al found no excess of symptoms in 21 firemen four weeks after a similar type of exposure. ${ }^{2}$ As part of a study of lung function in West Sussex firemen reported elsewhere, ${ }^{3}$ we obtained histories of past exposure to smoke, smoking habits, and respiratory symptoms in order to look for evidence of chronic lung disease resulting from the occupation of firefighting.

\section{Methods}

Initially there were 101 firemen in the study group, consisting of 94 randomly chosen volunteers and seven

Accepted 12 January 1987 self selected volunteers from six stations of the West Sussex Fire Brigade. ${ }^{3}$ The stations were selected to represent a cross section of the rural and urban areas covered by the service. The control group consisted of 69 volunteer men from a wide range of occupations who were acting as non-smoking controls in a study of the effects of cigarette smoking. At the start of the study subjects attended for lung function tests twice at an interval of a week, then every six months for two years, then annually for two years. ${ }^{3}$ At the initial attendance the Medical Research Council questionnaire on smoking habits and respiratory symptoms was completed. A smoker was defined as someone who had smoked at least one cigarette a day (or its equivalent in cigars or tobacco) for the previous year. Ex-smokers had not smoked for at least one month. Never smokers (referred to as non-smokers) had at no time fulfilled the criterion for being a smoker. Eight symptoms relating to pulmonary disease were chosen for study. These were:

Do you usually cough first thing in the morning in the winter? 
Do you usually cough during the day in winter?

Do you cough like this on most days for as much as three months in the year?

Do you usually bring up phlegm from your chest first thing in the morning in winter?

Do you usually bring up any phlegm from your chest during the day in winter?

Do you bring up phlegm like this on most days for as much as three months in the year?

Are you troubled by shortness of breath when hurrying on level ground or walking up a slight hill?

Does your chest ever sound whistling or wheezing?

For night workers the wording of the questions was adjusted appropriately. No questionnaire was used for the second session because this came only one week later. Thereafter, on the third and subsequent attendances, a follow up questionnaire was completed, asking about symptoms and smoking habits since the previous attendance. The questions on symptoms in the follow up questionnaire asked whether the following had occurred since the previous attendance:

Have you been coughing first thing in the morning? Have you been coughing during the day?

Have you been coughing like this on most days?

Have you been bringing up phlegm from your chest first thing in the morning?

Have you been bringing up phlegm from your chest during the day?

Have you been bringing up phlegm like this on most days?

Have you been troubled by shortness of breath when hurrying on level ground or walking up a slight hill?

Has your chest sounded wheezing or whistling?

Over the first year five firemen were lost to the study and these were excluded from the analysis. The remaining 96, consisting of 31 non-smokers, 25 exsmokers, and 40 smokers, were included. From the second to the fourth year a further seven were lost to the study. The remaining 89 were interviewed by one of us (KH) and information was obtained about being adversely affected by exposure to smoke and fumes in the past, use of breathing apparatus past and present, and any risk of exposure to smoke and fumes in current working practices.

\section{STATISTICAL ANALYSIS}

The frequency distributions of each symptom were entered in contingency tables and were analysed by the chi-squared test. ${ }^{4}$ Trend analysis of $2 \times 4$ contingency tables, testing for a rising frequency of positive responses in successive groups from left to right, was done on an Apricot F10 computer using the SPP statistical package by $P$ Royston obtained from Timberlake Clarke of Greenwich. It is based on the nonparametric analysis of variance by ranks.

\section{Results}

PERSONAL INTER VIEWS

A frequent comment was that $10-15$ years ago it used to be considered unmanly for a fireman not to be able to take a beating from the inhalation of smoke. Breathing apparatus was used only as a last resort and not if firemen could survive without it. A further factor inhibiting the regular use of breathing apparatus was the difficulty of servicing the older sets. Attitudes to this have now changed and the West Sussex Fire Brigade has for several years been extremely strict about the use of breathing apparatus and the associated control procedures. Each man was asked about past exposure to smoke and fumes and his use of breathing apparatus: 27 gave a history of having been moderately or severely affected by smoke or fumes at some time and a further 10 had been mildly affected. Twenty had not used breathing apparatus regularly in the past and 13 of these had been affected by smoke.

Table 1 Number of positive replies to questions on cough, phlegm, breathlessness, and wheeze from the MRC questionnaire at the first session in the 96 firemen who completed one year and in the control subjects

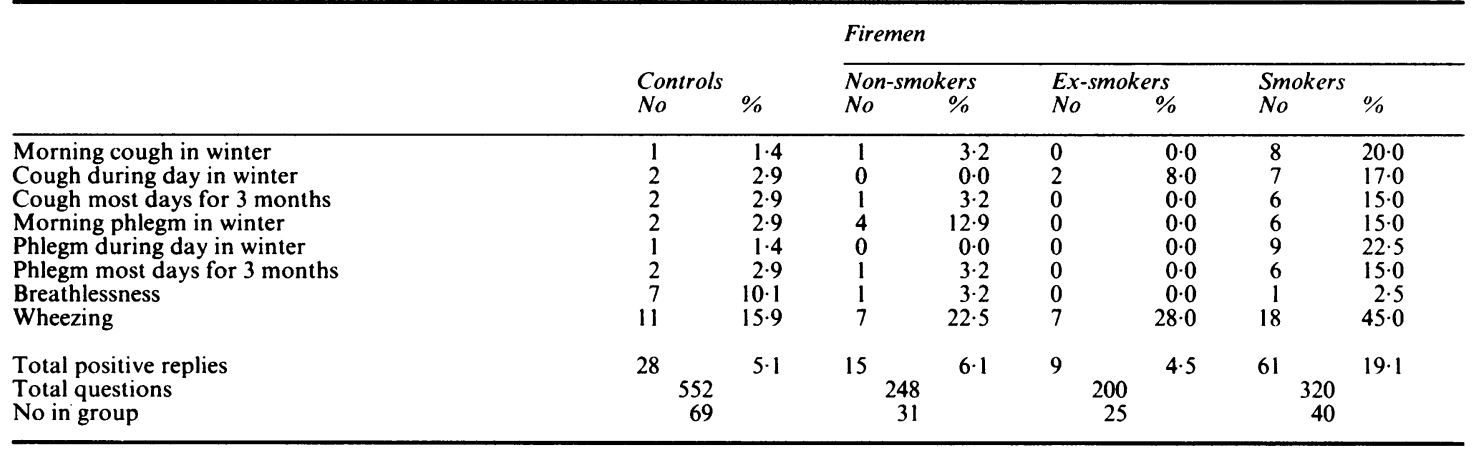


Table 2 Number of positive replies to questions on cough, phlegm, breathlessness, and wheeze from all the follow up questionnaires at the third and subsequent sessions in the 96 firemen who completed one year and in the control subjects

\begin{tabular}{|c|c|c|c|c|c|c|c|c|}
\hline & \multirow[b]{2}{*}{$\begin{array}{l}\text { Controls } \\
\text { No }\end{array}$} & \multirow[b]{2}{*}{$\%$} & \multicolumn{6}{|c|}{ Firemen } \\
\hline & & & \multicolumn{2}{|c|}{ Non-smokers } & Ex-smokers & $\begin{array}{c}\text { ers } \\
\%\end{array}$ & Smokers & $\%$ \\
\hline $\begin{array}{l}\text { Morning cough } \\
\text { Cough during day } \\
\text { Cough most days } \\
\text { Morning phlegm } \\
\text { Phlegm during day } \\
\text { Phlegm most days } \\
\text { Breathlessness } \\
\text { Wheezing }\end{array}$ & $\begin{array}{r}18 \\
21 \\
5 \\
14 \\
10 \\
4 \\
6 \\
12\end{array}$ & $\begin{array}{l}3 \cdot 9 \\
4 \cdot 5 \\
1 \cdot 1 \\
3 \cdot 0 \\
2 \cdot 3 \\
0 \cdot 9 \\
1 \cdot 3 \\
2 \cdot 6\end{array}$ & $\begin{array}{r}11 \\
16 \\
11 \\
15 \\
17 \\
7 \\
1 \\
5\end{array}$ & $\begin{array}{l}6 \cdot 3 \\
9 \cdot 1 \\
6 \cdot 3 \\
8.6 \\
9 \cdot 7 \\
4 \cdot 0 \\
0.6 \\
2.9\end{array}$ & $\begin{array}{r}16 \\
13 \\
1 \\
17 \\
12 \\
4 \\
0 \\
15\end{array}$ & $\begin{array}{r}11 \cdot 0 \\
9.0 \\
0.7 \\
11 \cdot 7 \\
8.3 \\
2.8 \\
0.0 \\
10.3\end{array}$ & $\begin{array}{r}43 \\
34 \\
18 \\
45 \\
22 \\
11 \\
9 \\
39\end{array}$ & $\begin{array}{r}19 \cdot 8 \\
15 \cdot 7 \\
8 \cdot 3 \\
20 \cdot 8 \\
10 \cdot 1 \\
5 \cdot 1 \\
4 \cdot 1 \\
18 \cdot 0\end{array}$ \\
\hline $\begin{array}{l}\text { Total positive replies } \\
\text { Total questions } \\
\text { No of interviews } \\
\text { No in group }\end{array}$ & \multicolumn{2}{|l|}{$\begin{array}{r}3696 \\
462 \\
69\end{array}$} & \multicolumn{2}{|c|}{$\begin{array}{r}1198 \\
175 \\
31\end{array}$} & \multicolumn{2}{|c|}{$\begin{array}{r}1160 \\
145 \\
25\end{array}$} & \multicolumn{2}{|c|}{$\begin{array}{r}1736 \\
217 \\
40\end{array}$} \\
\hline
\end{tabular}

\section{SYMPTOMS AND SMOKING HABIT}

The replies obtained to the MRC questionnaire (session 1) were analysed separately from those obtained to the follow up questionnaire (sessions 3 to 8 or 9) because the wording in the two questionnaires differed slightly. The replies obtained from session 3 and subsequent sessions were pooled to give data on symptoms occurring during the period of the study, whereas the MRC questionnaire at session 1 gave data on symptoms occurring before the study period.

Table 1 shows the number of positive replies to questions on symptoms from the MRC questionnaire at the first session in the control subjects and in the 96 firemen who completed one year, grouped by smoking habit. Table 2 shows the number of positive replies to questions on symptoms in the same groups to the follow up questionnaire at the third and subsequent sessions. A striking finding, more obvious in table 2 than in table 1 , is the tendency for the control subjects to have the fewer symptoms, non-smokers more, and smokers the most. In ex-smokers symptom frequency was rather variable but always less than in smokers. Tables 3 and 4 show the probabilities obtained for the chi-squared test on the frequency distribution of positive replies to the symptom questions. Also shown is the probability for the trend test on each question, looking for a rising frequency of positive replies reading from left to right across the table. The distribution of responses and the trends in the four subgroups taken together were significant for all symptoms ( $p<0.05$ to $p<0.0001$ ), except for breathlessness at the first session, which did not differ significantly between the goups.

At the first session (table 3) non-smokers did not differ significantly from the controls or the ex-smokers, except for morning phlegm in winter, ex-smokers having the least. Smokers had significantly more symptoms than non-smokers and ex-smokers, except for breathlessness.

At the third and subsequent sessions (table 4) smokers had significantly more symptoms than nonsmokers and ex-smokers, except for phlegm during the day. Non-smokers had five symptoms significantly more than controls and only wheezing was significantly less than in ex-smokers.

SYMPTOMS AND EXPOSURE TO SMOKE

The number of symptoms was compared in those giving a history of having been moderately or severely affected by smoke (subsequently called smoke affected) and those not so affected in the 89 men interviewed at four years. Table 5 shows the results in eight

Table 3 Values of probability p for the $\chi^{2}$ and trend tests for the frequency of positive responses to symptom questions shown in table 1

\begin{tabular}{lllllll}
\hline & $C+N+E+S$ & Trend & $C+N$ & $N+E$ & $N+S$ & $E+S$ \\
\hline Morning cough in winter & $<0.001$ & $<0.01$ & NS & NS & $<0.05$ & $<0.01$ \\
Cough during day in winter & $<0.05$ & $<0.01$ & NS & NS & $<0.01$ & NS \\
Cough most days for 3 months & $<0.01$ & $<0.01$ & NS & NS & NS & $<0.05$ \\
Morning phlegm in winter & $<0.05$ & $<0.05$ & $<0.05$ & $<0.05$ & NS & $<0.05$ \\
Phlegm during day in winter & $<0.0001$ & $<0.0001$ & NS & NS & $<0.01$ & $<0.01$ \\
Phlegm most days for 3 months & $<0.05$ & $<0.01$ & NS & NS & $<0.05$ & NS \\
Breathlessness & NS & NS & NS & NS & NS & NS \\
Wheezing & $<0.01$ & $<0.001$ & NS & NS & $<0.05$ & NS \\
Total symptoms & $<0.0001$ & $<0.0001$ & NS & NS & $<0.0001$ & $<0.0001$ \\
\hline
\end{tabular}

$\mathrm{C}=$ Controls, $\mathrm{N}=$ non-smoking firemen, $\mathrm{E}=$ ex-smokers, $\mathrm{S}=$ smokers, $\mathrm{NS}=$ not significant at $5 \%$. The trend test was for a rising frequency of positive replies, reading from left to right across the four subgroups in table 1 . 
Table 4 Values of probability $p$ for the $\chi^{2}$ and trend tests for the frequency of positive responses to symptom questions shown in table 2

\begin{tabular}{|c|c|c|c|c|c|c|}
\hline & $C+N+E+S$ & Trend & $C+N$ & $N+E$ & $N+S$ & $E+S$ \\
\hline $\begin{array}{l}\text { Morning cough } \\
\text { Cough during day } \\
\text { Cough most days for } 3 \text { months } \\
\text { Morning phlegm } \\
\text { Phlegm during day } \\
\text { Phlegm most days } \\
\text { Breathlessness } \\
\text { Wheezing }\end{array}$ & $\begin{array}{l}<0.0001 \\
<0.0001 \\
<0.0001 \\
<0.0001 \\
<0.0001 \\
<0.001 \\
<0.01 \\
<0.0001\end{array}$ & $\begin{array}{l}<0.0001 \\
<0.0001 \\
<0.0001 \\
<0.0001 \\
<0.0001 \\
<0.001 \\
<0.05 \\
<0.0001\end{array}$ & $\begin{array}{l}\text { NS } \\
<0.05 \\
<0.001 \\
<0.05 \\
<0.0001 \\
<0.01 \\
\text { NS } \\
\text { NS }\end{array}$ & $\begin{array}{l}\text { NS } \\
\text { NS } \\
<0.01 \\
\text { NS } \\
\text { NS } \\
\text { NS } \\
\text { NS } \\
<0.01\end{array}$ & $\begin{array}{l}<0.001 \\
<0.05 \\
\text { NS } \\
<0.001 \\
\text { NS } \\
\text { NS } \\
<0.05 \\
<0.0001\end{array}$ & $\begin{array}{l}<0.5 \\
<0.5 \\
<0.01 \\
<0.05 \\
\text { NS } \\
\text { NS } \\
<0.01 \\
<0.05\end{array}$ \\
\hline Total symptoms & $<0.0001$ & $<0.0001$ & $<0.0001$ & NS & $<0.0001$ & $<0.0001$ \\
\hline
\end{tabular}

$\mathrm{C}=$ Controls, $\mathrm{N}=$ non-smoking firemen, $\mathrm{E}=$ ex-smokers, $\mathrm{S}=$ smokers, $\mathrm{NS}=$ not significant at $5 \%$. The trend test was for a rising frequency of positive replies, reading from left to right across the four subgroups in table 2 .

$2 \times 2$ tables, which indicate that in all firemen taken together symptoms are 1.6 times more frequent in the smoke affected group than in those not affected at sessions 3 to $8(p<0.001)$ but do not differ significantly at session $1(\mathrm{p}>0.05)$. Obviously the distribution of smoking habits could affect this observation and these are shown in table 6 as a $2 \times 3$ table. The proportion of smokers is twice as high in those not affected by smoke or fumes as among those that have been, so that any resulting bias from the effects of tobacco smoke would tend to reduce the observed difference. In fact the distribution of smoking habits does not differ significantly between the two groups ( $p>0.05$ ). Table 5 also shows the results grouped by smoking habit. In non-smokers smoke affected firemen have 5.7 times more symptoms at sessions 3 to 8 than those not affected $(p>0 \cdot 001)$ but only $2 \cdot 3$ times more at session $1(p>0.05)$. In ex-smokers there are no significant differences in symptom frequency in relation to having been affected by smoke. Among smokers, the smoke affected firemen have from 1.7 to $2 \cdot 3$ times more symptoms than those not affected $(\mathrm{p}<$ $0 \cdot 001)$.

\section{LUNG FUNCTION TESTS}

There was no significant difference in any of the lung function tests between the smoke-affected and the non-affected group. The tests are described elsewhere. ${ }^{3}$

\section{Discussion}

Although lung function in the firemen deteriorates with age more slowly than in the controls, ${ }^{3}$ nevertheless the firemen have more symptoms. There is a clear gradient of symptom frequency, control subjects having the least, non-smoking and ex-smoking firemen taken together more, and smokers the most symptoms. In addition, there is an increase in symptoms in smoke affected men, suggesting that exposure either to smoke at work or from tobacco may contribute to their causation. The exception to this is breathlessness, which is less frequent in firemen probably because of their physical fitness. Symptoms increase 2.9 times from control to non-smoking firemen at sessions 3 to 8 (table 2) and 1.8 times from non-smoking firemen to smokers, suggesting that occupation is not dissimilar to smoking as a cause of symptoms during the study. When control subjects (tables 1 and 2) are compared with non-smoking firemen who have not been affected by smoke (table 5), their frequency of symptoms are similar, $5.1 \%$ and $2.4 \%$ compared with $3.9 \%$ and $2.3 \%$ respectively ( $p>0.05$ ). Thus it is only those

Table 5 Replies to questions on symptoms in the 89 firemen who completed four years related to smoking habit and history of having been affected by smoke

\begin{tabular}{|c|c|c|c|c|c|c|c|}
\hline \multirow[b]{2}{*}{ Smoking habit } & \multirow[b]{2}{*}{ Affected by smoke } & \multicolumn{3}{|c|}{$\begin{array}{l}\text { Session I } \\
\text { All symptoms }\end{array}$} & \multicolumn{3}{|c|}{$\begin{array}{l}\text { Sessions } 3 \text { to } 8 \\
\text { All symptoms }\end{array}$} \\
\hline & & Yes $(\%)$ & No & $p$ & Yes (\%) & No & $p$ \\
\hline All combined & $\begin{array}{l}\text { Yes } \\
\text { No }\end{array}$ & $\begin{array}{l}28(13.0) \\
49(9.9)\end{array}$ & $\begin{array}{l}188 \\
447\end{array}$ & NS & $\begin{array}{l}149(11 \cdot 6) \\
211(7 \cdot 2)\end{array}$ & $\begin{array}{l}1139 \\
2717\end{array}$ & $<0.0001$ \\
\hline Non-smoker & $\begin{array}{l}\text { Yes } \\
\text { No }\end{array}$ & $\begin{array}{l}8(9 \cdot 1) \\
6(3 \cdot 9)\end{array}$ & $\begin{array}{r}80 \\
146\end{array}$ & NS & $\begin{array}{l}68(13 \cdot 1) \\
21(2 \cdot 3)\end{array}$ & $\begin{array}{l}452 \\
875\end{array}$ & $<0.0001$ \\
\hline Ex-smoker & $\begin{array}{l}\text { Yes } \\
\text { No }\end{array}$ & $\begin{array}{l}3(3 \cdot 8) \\
6(5 \cdot 8)\end{array}$ & $\begin{array}{l}77 \\
98\end{array}$ & NS & $\begin{array}{l}32(6 \cdot 7) \\
48(7 \cdot 7)\end{array}$ & $\begin{array}{l}448 \\
576\end{array}$ & NS \\
\hline Smoker & $\begin{array}{l}\text { Yes } \\
\text { No }\end{array}$ & $\begin{array}{l}17(35.4) \\
37(15.4)\end{array}$ & $\begin{array}{r}31 \\
203\end{array}$ & $<0.01$ & $\begin{array}{r}49(17 \cdot 0) \\
142(10 \cdot 1)\end{array}$ & $\begin{array}{r}288 \\
1408\end{array}$ & $<0.001$ \\
\hline
\end{tabular}

NS $=$ Not significant at $5 \%$. 
Table $63 \times 2$ contingency table for the 89 firemen who completed four years, according to history of having been affected by smoke, grouped by smoking habit

\begin{tabular}{lllll}
\hline & Non-smoker & Smoker & Ex-smoker & Totals \\
\hline Affected & $11(40 \cdot 7)$ & $6(22 \cdot 2)$ & $10(37 \cdot 0)$ & 27 \\
Not affected & $19(30 \cdot 6)$ & $30(48 \cdot 4)$ & $13(21 \cdot 0)$ & 62 \\
Totals & $30(33 \cdot 7)$ & $36(40 \cdot 4)$ & $23(25 \cdot 8)$ & 89 \\
\hline
\end{tabular}

Percentage of rows in parentheses. Not significant at $5 \%$ by chi square test.

firemen who have been affected by smoke or who are smokers, or both, who have an excess of symptoms. Ex-smokers have a similar frequency of symptoms to non-smokers (tables 1 and 2) being significantly more only for wheezing. They have appreciably fewer symptoms than smokers, the difference being significant for most symptoms. Thus on stopping smoking most excess symptoms are lost, showing one of the benefits of giving up the habit.

To make the essential points of table 5 more easily understood, they have been summarised in the figure as a bar chart. Consider the first session shown in the left hand half of the figure. In non-smokers, having been affected by smoke increases symptoms by $2 \cdot 3$ times, whereas smoking increases symptoms 3.9 times in those not affected by smoke. In smokers who have also been affected by smoke symptoms are increased $9 \cdot 1$ times. Considering next sessions 3 to 8 shown in the right hand half of the figure, it may be seen that in nonsmoking firemen symptoms are 5.7 times more frequent in those affected by smoke than in those not affected. A similar increase of 4.4 times is seen as a result of smoking in those not affected by smoke. Thus exposure to either type of smoke has a similar effect in this group of men, increasing symptoms about five times. In smokers who have also been affected by smoke symptoms are 7.4 times more frequent than in unaffected non-smokers. Thus the combined effects of both types of smoke are multiplicative at session 1 but less than additive in sessions 3 to 8 . Fletcher $e t$ al have

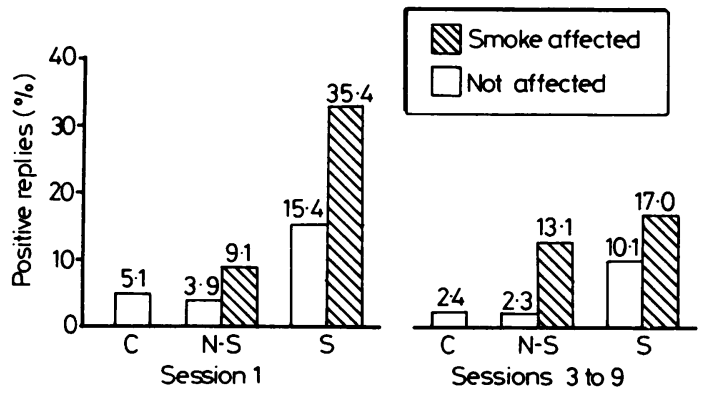

Positive replies to symptom questions in control subjects (C), firemen who are non-smokers $(N-S)$, and firemen who smoke (S). Firemen have been divided into those affected by smoke in past and those not affected. shown the existence of a group susceptible to the effects of cigarette smoke, ${ }^{5}$ and it may be that the same group is also susceptible to the effects of smoke and fumes arising from fires.

In ex-smokers there is no difference in symptoms between those affected and those not affected by smoke (table 5). Perhaps the improvement in symptoms that follows the cessation of smoking masks any difference that may have been present.

Thus although West Sussex firemen have better than average lung function and a lower rate of loss of function with age than control subjects ${ }^{3}$ they nevertheless have more respiratory symptoms; this is particularly true of those with a history of having been affected by smoke in the past. Men may still occasionally be exposed to smoke and fumes while not wearing breathing apparatus, despite its general availability. This may occur in the following circumstances: (1) an officer entering a building to make a rapid initial assessment of a fire; (2) an immediate rescue of a trapped person in danger of his life; (3) an officer reassessing a fire coming under control; and (4) those at the site of a fire may have smoke or fumes blown towards them as a result of a change in wind direction, or there may be a build up in the surrounding air. The long term effects on symptoms of having been affected by smoke and fumes at work are similar to those of cigarette smoking in this group of men, whereas nonsmokers who have not been affected by smoke or fumes have no excess of symptoms over the control subjects. Thus although the occupation of firefighting has the potential to cause chronic lung damage, at present this appears to be effectively controlled by the regular use of breathing apparatus.

Requests for reprints to: Dr K Horsfield.

In addition to the Colt Foundation, who contributed the major part of the funding for this study, we also thank the following companies for financial support: A Grantham, British Petroleum, Chubb Fire Security, Helmets, Interlink Import-Export, Mather and Platt, Merryweather and Sons, Siebe Gorman, Metal Box, and Shell UK.

\section{References}

1 Axford AT, McKerrow CB, Parry Jones A, Le Quesne PM. Accidental exposure to isocyanate fumes in a group of firemen Br J Ind Med 1976;33:65-71.

2 Tashkin DP, Genovesi MG, Chopra S, Coulson A, Simmons M Respiratory status of Los Angeles firemen. Chest 1977;71: 445-9.

3 Horsfield K, Guyatt A, Cooper F, Buckman M, Cumming G. A four year study of lung function in West Sussex firemen. Br J Ind Med 1987;45:116-21.

4 Snedecor GW, Cochren WG. Statistical methods. Iowa: Iowa State University Press, 1980.

5 Fletcher C, Peto R, Tinker C, Speizer FE. The natural history of chronic bronchitis and emphysema. Oxford: Oxford University Press, 1976. 